\title{
CARONTE project: Creating an Agenda for Research on Transportation Security
}

\author{
Jorge León Bello
}

Project Manager, ITENE - Instituto Tecnológico del Embalaje, Transporte y Logística, Spain

Emilio González Viosca

R\&I Department, ITENE - Instituto Tecnológico del Embalaje, Transporte y Logística, Spain

\section{SUMMARY}

Europe's prosperity relies on effective transport systems. Any attacks and disturbances to land freight and passenger transport would have significant impact on economic growth, territorial cohesion, social development and the environment. Unfortunately, there are weaknesses in the land transport security.

The objective of CARONTE project is define a future research agenda for security in land transport that focuses on core gaps caused by emerging risks while avoiding any doublingup of research elsewhere.

Its research agenda will cover all threats, including cyber-crime, and security aspects across all modes of land transportation. At the same time, it will respect the fundamental human rights and privacy of European citizens. The step-by-step method of CARONTE's consortium has analyzed the state of the art and emerging risks; has identified gaps, analyses and assessments of potential solutions; and has produced an overall research agenda for the future.

CARONTE's results will answer the following questions among others:

- Which existing research projects merit a follow up and extension?

- Where are the combinations or synergy effects to be attended?

- Which themes and topics should be elaborated in new research projects?

- Who should be involved and integrated in future research projects (stakeholders, authorities, etc.)?

The CARONTE consortium includes universities and research institutes, companies, and end-users providing with experience in research and consultancy in transportation, logistics, infrastructure management, security and communications. ITENE - Instituto Tecnológico del Embalaje, Transporte y Logística- has been one of the Project partners among a total of 11 members from eight different countries in the European Union which have also been supported via a High Level Advisory Board. 


\section{INTRODUCTION}

\subsection{Background}

Europe's prosperity relies on effective and safe transport systems. Any attacks or disturbances to land freight or passenger transport would have a major impact on economic growth, territorial cohesion, social development, and even on the life and health of European citizens. Unfortunately, there are weaknesses in Europe's land transport security, and these issues are diverse and complex. Continuous and coordinated efforts are needed to address them.

For 18 months, the CARONTE project has been working on issues like "What are the security challenges to land transportation and how can a strategic research agenda for the EU efficiently help to find answers?" During this time the consortium has carried out analyses on: the state of the art in securing land transportation, the threats facing the sector and the current gaps and requirements for future research. On the basis of these assessments CARONTE has defined a future research agenda for land transport security that focuses on the sector's emerging risks while avoiding any doubling-up of research elsewhere. Special care has been taken to base the research agenda on the concept of fluent and efficient flow of passengers and goods, while bearing in mind the relevant ethical, societal and legal aspects.

Overall, CARONTE aims at contributing to European research planning by providing insight into burning issues and possible research avenues in the field of land transport security. Thereby, the CARONTE's strategic research agenda covers the following areas.

- Road transport

- Rail transport

- Logistics

- Interfaces between transport modes, including aviation and maritime transport

- Cyber security in transportation

- Cross-cutting issues like knowledge sharing, ethical and privacy issues, crisis management, life-cycle costs etc.

\subsection{The CARONTE Approach}

Before any work was begun, the CARONTE consortium had to define common terms to forge a clear picture of their meanings in a land transport security context. Thus in the context of this project, the following terms were applied:

In addition to that, a working definition of what "security" means had to be determined to determine the scope of the project. From all conceivable security issues, the CARONTE project focusses those that are caused by willful acts of persons (mainly with criminal or terrorist intents). This definition of security is illustrated in Figure 1. 


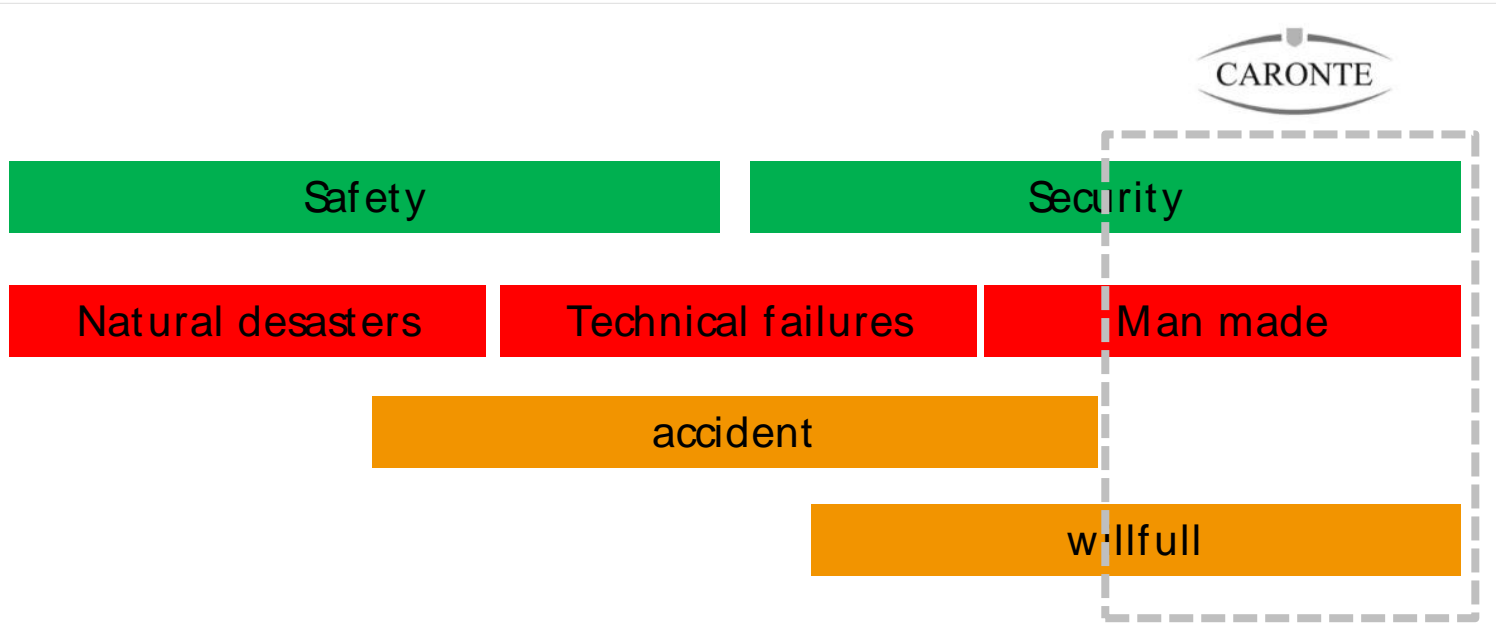

Fig. 1 - Defining the scope of the CARONTE project

\section{IDENTIFICATION OF GAPS}

An important task of the project was the identification and analysis of the current gaps and requirements in security issues of land transport including intermodal solutions and interfaces between the modes and nodes to aviation and maritime transport.

To fulfil this objective several consultation processes have been performed through the knowledge of consortium partners, national and international experts. The knowledge of the partners was established in a first step through a matrix analysis as the basis for the following consultancy of the experts through structured interviews and questionnaires in the case of national experts and a workshop in the case of international experts.

From all the gaps and requirements identified and analysed, the top ten gap and requirement topics of matrix, questionnaires and expert workshop are presented in the following tables:

\begin{tabular}{|l|}
\hline \multicolumn{1}{|c|}{ Gaps - Matrix analyses } \\
\hline Cybersecurity and cybercrime \\
\hline Commune standards and protocols \\
\hline Detection and Monitoring Technology \\
\hline Prevention: developing tools in risk assessment \\
\hline Crisis Management \\
\hline Physical Protection \\
\hline $\begin{array}{l}\text { Organizational protection in case of attack and hijacking (staff, passenger, vehicle and } \\
\text { logistic) }\end{array}$ \\
\hline Security personnel \\
\hline $\begin{array}{l}\text { Complete security chain in case of attack, hijacking (staff and vehicle) and manipulation } \\
\text { from staff. }\end{array}$ \\
\hline $\begin{array}{l}\text { Closed loading units (seals) in case of attack (logistic, cargo and vehicle), manipulation } \\
\text { and theft. }\end{array}$ \\
\hline
\end{tabular}

Table 1 - Top gaps and requirement from matrix analyses 


\begin{tabular}{|l|}
\hline \multicolumn{1}{|c|}{ Gaps - Questionnaire } \\
\hline Financial support of authorities to implement security measures \\
\hline Ethical and Regulation concerns stop technologies \\
\hline Detection and Monitoring Technology \\
\hline Budget to develop technologies \\
\hline Coordination - Lesson Learned share between all actors in land transport chain \\
\hline Cybersecurity and cybercrime \\
\hline Lack of awareness \\
\hline $\begin{array}{l}\text { Prevention: developing tools in risk assessment (proactive assessment of possible } \\
\text { vulnerabilities) }\end{array}$ \\
\hline Training \\
\hline Commune standards and protocols \\
\hline
\end{tabular}

Table 2 - Top ten gaps and requirements from questionnaires

\begin{tabular}{|c|}
\hline Gaps - Workshop \\
\hline $\begin{array}{l}\text { Lessons learned or existing solutions from other sectors (i.e. aero, safety process) to } \\
\text { transport sector }\end{array}$ \\
\hline Open Systems \\
\hline Education and Training (TTP - Tactics, techniques \& procedures) \\
\hline Logistics - Cyber Protection \\
\hline Interface Port - Cyber protection - Power Supply \\
\hline Cyber Security integrate into Infrastructure Risk assessment \\
\hline $\begin{array}{l}\text { Communication between countries \& organization's in emergency situation (e.g. Mont } \\
\text { 'Blanc) }\end{array}$ \\
\hline Awareness \\
\hline Standards \& Rules \\
\hline Rising threat from terrorism or organized crime \\
\hline
\end{tabular}

Table 3 - Top ten gaps and requirements from expert workshop

\section{PRIORITIZATION METHODOLOGY}

The prioritization was done in the following steps:

- A "Gap and Requirement Analysis" was carried out evaluating the existing gaps in transport security

- A “Approaches and Solutions Identification” took place in order to evaluate potential solutions to identify items for the research roadmap.

- A "Weighted-Bit Assessment Table for Land Transport Problems and Solutions" was developed which allows gathering information about the topics identified in a structured way.

- Approx. 120 existing research projects were analysed for their association with the topics analysed. 
- Relevant European policies were analysed for statements concerning research priorities.

- National and European research programmes were scanned regarding their priorities in the context of land transport security.

- Existing centres of excellence in this area were also described.

The criteria for prioritization were designed to take into account as much of the information previously gathered as possible. By a deliberate choice, no "mathematical system" was devised to "calculate" a final priority score from the individual judgements, as this would only simulate calculability where in fact expert opinion is key.

The individual criteria, were:

\begin{tabular}{|l|l|}
\hline \multicolumn{1}{|c|}{$\mathbf{1}$} & \multicolumn{1}{c|}{ Expert opinion } \\
\hline Top priority & Has been highly prioritised by experts in workshops. \\
\hline High priority & Has been mentioned by experts. \\
\hline Other important issues & $\begin{array}{l}\text { Received little attention from the experts involved in } \\
\text { CARONTE. }\end{array}$ \\
\hline
\end{tabular}

\begin{tabular}{|l|l|}
\hline \multicolumn{1}{|c|}{$\mathbf{2}$} & $\begin{array}{c}\text { "Is this a burning issue to be dealt with or is it less } \\
\text { urgent or less important?" }\end{array}$ \\
\hline Top priority & "1 - high impact issue" \\
\hline High priority & "1 - high impact issue" OR " $0.5-$ medium impact issue" \\
\hline Other important issues & " $0.5-$ - medium impact issue" OR " 0 - low impact issue" \\
\hline
\end{tabular}

\begin{tabular}{|l|l|}
\hline \multicolumn{1}{|c|}{$\mathbf{3}$} & "Projects dealing with the need or providing solutions" \\
\hline Top priority & Insufficient research projects. \\
\hline High priority & There are research projects which deal with this issue. \\
\hline Other important issues & Item sufficiently addressed by current research. \\
\hline
\end{tabular}

\begin{tabular}{|l|l|}
\hline \multicolumn{1}{|c|}{$\mathbf{4}$} & \multicolumn{1}{c|}{$\begin{array}{c}\text { Research is essential for meeting the need or } \\
\text { requirement. }\end{array}$} \\
\hline Top priority & Research is urgently needed. \\
\hline High priority & Research might be helpful to address the need. \\
\hline Other important issues & $\begin{array}{l}\text { Measures other than research are better suited to close the } \\
\text { gap OR research might just play a supporting role. }\end{array}$ \\
\hline
\end{tabular}

\begin{tabular}{|l|l|}
\hline \multicolumn{1}{|c|}{$\mathbf{5}$} & \multicolumn{1}{c|}{ Connection to land transport } \\
\hline Top priority & Needs research specifically for land transport issues. \\
\hline High priority & Needs some adaption for land transport issues. \\
\hline Other important issues & General problem, not specific for land transport. \\
\hline
\end{tabular}

\begin{tabular}{|l|l|}
\hline \multicolumn{1}{|c|}{$\mathbf{6}$} & \multicolumn{1}{|c|}{$\begin{array}{c}\text { General impression from the previous analysis of the } \\
\text { state of the art }\end{array}$} \\
\hline Top priority & $\begin{array}{l}\text { No affordable solution exists to deal with the threat. There } \\
\text { is a serious lack of knowledge regarding the threat itself as } \\
\text { well as measures to meet the urgent needs. }\end{array}$ \\
\hline
\end{tabular}




\begin{tabular}{|l|l|}
\hline High priority & $\begin{array}{l}\text { There are some solutions available to deal with the threat. } \\
\text { But there is still a lot to be done regarding the development } \\
\text { of new solutions or of developing organisational, social or } \\
\text { political measurements. }\end{array}$ \\
\hline Other important issues & $\begin{array}{l}\text { The threat is well described and affordable solutions exist } \\
\text { to deal with it. Information about possible solutions is } \\
\text { sufficiently disseminated among the people who need to } \\
\text { know. National or international standards and processes are } \\
\text { in place. Relevant authorities and first responders work } \\
\text { successfully together. }\end{array}$ \\
\hline \hline & \multicolumn{1}{|c|}{ Connection to current policies } \\
\hline Top priority & $\begin{array}{l}\text { Is frequently mentioned in policy papers OR is too new to } \\
\text { be mentioned in policy papers. }\end{array}$ \\
\hline High priority & Is mentioned in policy papers. \\
\hline Other important issues & Is not considered to be a priority in policy papers. \\
\hline
\end{tabular}

Table 4 - Criteria for prioritization

\section{RESULTS OF THE PRIORITIZATION}

As a result of the process described above, the following priority lists were generated:

- Top priority issues

○ Staying operational in the event of a cyber-incident

- Timely and efficient threat detection

- Special security problems of railways as open systems

- High priority issues

- Balancing security requirements and privacy demands of passenger

- Security awareness of personnel and customers

- Crisis Management

- Security by design

- Security retrofit (ICT)

- Secure communication links for traffic control systems

- Protection of autonomous vehicles against cyber-attacks

- Secure critical infrastructures (cyber/road system)

- Other important issues

- Sharing of best practices among stakeholders

- Effective communication between companies, police and other administrations about threats

- Efficient security solutions (lifecycle costs)

- Sufficient financial support for the implementation of security measures 
- Sufficient financial support for security research

- Applying the best security measures and technologies

- Securing legacy systems (physical)

- Secure critical infrastructures (especially tunnels and bridges)

○ Data security / privacy

- User-friendliness of security systems

- Keeping pace with developing risks and threats

- Secure communication in freight transport chains

- Limiting damage in the case of an attack

- Professional security management

- Common standards and protocols for rail security

- Secure truck parking and protection of driving personnel

- Protection against inside threats

- Avoidance of dangerous routes or parking lots

\section{DEVELOPMENT OF A RESEARCH AGENDA FOR SECURITY ISSUES IN LAND TRANSPORT}

One of the core aims of the CARONTE project was to support future research planning on a European level. Consequently, it was of high importance to present the results of CARONTE in a way that is both relevant and compatible with current European research programmes, with HORIZON 2020 being at the centre of these considerations.

During the process described in the previous sections, relevance for European research planning had been assured in various ways, e.g.:

- detailed analysis of the state-of-the-art, with a special focus on current and recently completed European research projects,

- collection and evaluation of the views of a large number of experts and stakeholders,

- and alignment of the issues prioritised with European policies.

In this regard, in order to increase the compatibility of the research ideas identified, they were categorised along the programme lines of HORIZON 2020, and more specifically along the build-up of the work programmes within the security challenge.

These were divided into the following areas:

- Critical Infrastructure Protection (CIP)

- Disaster-resilience: safeguarding and securing society (DRS)

- Fight against crime and Terrorism (FCT)

- Border Security and External Security (BES)

- General Matters (GM)

- Digital Security Focus Area (DS) 
The analysis of the categorisation of the research ideas previously identified gave the following results: "Fight against crime and Terrorism" (FCT) is the field most addressed by the research ideas collected during the CARONTE project. This is due to the focus of the project on malicious attacks, crime, and accidents caused by human error. Nevertheless, "Critical Infrastructure Protection" (CIP) and "Disaster-resilience: safeguarding and securing society" (DRS) were also found to be well covered by the research ideas collected. In this context, it was noted that a clear attribution of research ideas to either CIP or DRS was not always possible. While a number of ideas touching ICT could be attributed to the "Digital Security Focus Area" (DS), "Border Security and External Security" (BES) was clearly out of the scope of the CARONTE project.

\section{CONCLUSIONS}

Easy, efficient, safe and secure transportation is a core factor for European growth, collaboration and employment, and thus for the Europe 2020 strategy. Land transportation has two main security challenges: to avoid interruptions of transport and ensure the free flow of freight and passengers which guarantee supply to Europe's populace, and to avoid that transportation modes become open to avenues of attack.

In this regard, CARONTE project has helped to tackle these challenges by producing a research agenda for security in land transport that focuses on the core relevant gaps caused by emerging risks.

The Research Agenda developed shows how to build up the needed European capabilities to ensure efficient Europe-wide security in land transportation and how to mitigate impact in case of incidences. It also provides global guidelines on enhancing the surveillance of the land transport infrastructure.

\section{ACKNOLEDGEMENTS}

The present work has been elaborated in the framework of the CARONTE Project (Grant Agreement number: 606967), which was supported by the European Commission through the EU Seventh Framework Programme. The CARONTE consortium included universities and research institutes, companies, and end-users providing with experience in research and consultancy in transportation, logistics, infrastructure management, security and communications. In addition, to ensure practical use and acceptance of the final recommendations, end-users such as transportation companies, infrastructure managers, terminal operators, customs as well as the suppliers of security and transportation equipment which were linked to the project via its High Level Advisory Board. 


\section{REFERENCES}

CARONTE (2014) "Creating an Agenda for Research on Transportation Security” Seventh Framework Programme (FP7). Grant agreement no.: 606967. [Online]. Available at <www. caronte-project.eu>. 